\title{
A recuperação da cultura científica: obras comemorativas
}

\author{
Pandora Guimarães
}

Gabinete de Comunicação da AULP Mestranda em Comunicação, Cultura e Tecnologias da Informação, ISCTE-IUL

Desde 2007 a AULP é responsável pela edição de obras comemorativas que contribuem para engrandecer o panorama literário e científico nos países onde se fala a língua portuguesa. No ano em que a AULP completa 30 anos, reúne dezasseis obras publicadas nos Encontros anuais da associação.

Nos últimos anos, desde 2007, a AULP vem editando um conjunto de obras comemorativas nos seus encontros anuais, onde a dispersão dos seus membros leva a que os encontros assumam um carater itinerante e reúnam contribuições originárias das diversas latitudes, enriquecendo o debate científico e favorecendo a relação entre os membros da comunidade.

Reedições fac-similadas de obras inacessíveis, livros científicos de reconhecido valor já desaparecidos ou cuja oportunidade se faz sentir são distribuídas gratuitamente por todos os membros.

O projeto surge em 2007 durante os preparativos do XVII Encontro da AULP. A associação preparava-se esse ano para regressar, pela primeira vez desde 26 de novembro de 1986, ao país onde fora assinado a ata da constituição - Cabo-Verde. Com apenas sete meses de existência, a Universidade de Cabo Verde decidiu fazer parte da família AULP, filiando-se à associação, e abraçou o desafio de receber o XVII Encontro da AULP, que teve como temática "A Universidade em Rede".

É neste contexto que a AULP decide editar uma obra comemorativa de elevada importância cultural e científica tanto para o país de acolhimento, como para as instituições de ensino superior presentes no encontro. "Santiago de Cabo Verde: A Terra e os Homens" é assim a primeira obra comemorativa lançada, resultado da colaboração entre várias instituições de ensino superior e de investigação: a AULP, o Centro de Estudos Geográficos das Universidade de Lisboa (CEG-UL), o Instituto de Investigação Científica e Tropical (IICT), a Universidade do Algarve (UALG) e a Universidade de Cabo Verde (UNICV).

Com uma tiragem de 1000 exemplares, e mais de 500 páginas com estampas e mapas no final deste livro de capa rija, trata-se de um texto editado pela antiga Junta de Investigações do Ultramar, e há muito esgotado, que reúne um conjunto de informações, de reflexões e de sugestões interpretativas ainda hoje 
com enorme interesse e frequentemente procuradas pelos investigadores que, na atualidade, orientam a sua atenção para o estudo do território cabo-verdiano, dos seus recursos, das suas gentes e das suas atividades.

O livro que se reproduziu sobre a Ilha de Santiago, em Cabo Verde, constitui a tese de doutoramento de Ilídio do Amaral, apresentada na Faculdade de Letras de Lisboa em 1964. O autor desta obra faz parte do conjunto de universitários que dedicaram uma parcela significativa da sua atividade de investigação científica aos problemas dos territórios africanos que, até 1975, estiveram sob administração portuguesa. O labor desenvolvido por aquele conjunto de investigadores permitiu um melhor conhecimento dos territórios africanos em diversos domínios inseridos nas ciências naturais e nas ciências sociais.

A agronomia, a zootecnia são alguns dos domínios privilegiados nesse movimento que permitiu alargar os mundos do conhecimento e que constitui um importante legado acolhido em revistas, livros, documentos, memórias, relatórios, projetos, mapas, etc.

Note-se que Ilídio do Amaral dedicou toda a sua vida ao ensino e à investigação científica na área da geografia, explorando a perspetiva monográfica bem afirmada pela Escola de Geografia de Lisboa - sendo este texto publicado sobre a Ilha de Santiago um exemplo inovador.

No ano seguinte, por ocasião do XVIII Encontro da AULP, é publicado o livro "Sermão de S. António aos Peixes, Sermão da Sexagésima, Sermão do Demónio Mudo", edição lançada no dia 10 de Setembro de 2008 na Biblioteca Nacional de Brasília, país onde decorreu o encontro. Associando-se às diversas iniciativas que integram a comemoração dos 100 anos desde o nascimento do Padre António Vieira, a AULP participou no lançamento desta obra.

António Vieira nasceu em 1608, viveu 89 anos e, nesse longo percurso revelou-se um cidadão notável no seu tempo. A sua vida foi preenchida por sucessivos confrontos com os valores prevalecentes na sociedade seiscentista. Originário de uma família humilde, António Vieira circulou no seu mundo associando parte substancial da sua ação à crítica social, utilizando os sermões, normalmente de conteúdo metafórico, como principal instrumento de influência, de persuasão e de transmissão das suas ideias.

Intervindo de forma ímpar no panorama da cultura e da língua portuguesa, assumiu de forma decisiva uma postura de crítica social, fortemente desvalorizada na época. Tomou contacto com algumas das comunidades que se inserem nos dias de hoje no mundo da língua portuguesa: Portugal, Brasil, Cabo Verde, tendo acompanhado de perto o enorme fluxo de africanos que, nesses anos de seiscentos, foram transferidos dos territórios de África para as costas do Brasil.

Com ilustrações originais de João Alvim, este livro reproduz assim três sermões que constituem uma amostra dos 203 que o Padre António Vieira passou à 
escrita - Sermão de S. António aos Peixes, Sermão da Sexagésima e Sermão do Demónio Mudo.

A concretização desta edição de grande importância para as comunidades de língua portuguesa resulta da colaboração de várias instituições: a AULP, a ANDIFES (Associação Nacional dos Dirigentes das Instituições Federais de Ensino Superior, Brasil), a Fundação Luso-Brasileira, o Instituto Camões, a Universidade do Algarve e a Universidade Estadual Paulista (UNESP).

Em 2009 são editadas duas obras comemorativas "Etnias e Culturas de Angola", e "Carta Fitogeográfica de Angola", que vieram enriquecer a conferência internacional organizada pela AULP em conjunto com a Universidade Agostinho Neto, Angola.

O XIX Encontro da AULP teve como tema "Direito, Cidadania e Desenvolvimento", dando particular atenção a dois sectores, a promoção da educação e da cidadania a partir das novas tecnologias e, a reflexão sobre os modelos de desenvolvimento, procurando identificar as potencialidades da maior intersecção entre a Universidade e a sociedade, passíveis no futuro de maior aprofundamento. Foi ainda abordado no painel final do Encontro, a problemática da língua e da cultura como meio de promover o melhor relacionamento nos âmbitos científico, tecnológico, artístico, cultural e diplomático entre os povos dos países da CPLP.

O livro "Etnias e Culturas de Angola" é da autoria de José Redinha, grande pesquisador e etnólogo português. Com 250 figuras e 2 mapas, a concretização deste projeto editorial foi resultado de uma colaboração profícua entre várias instituições: Ministério da Cultura de Angola, Banco Nacional de Angola, Universidade Agostinho Neto (Faculdade de Letras e Ciências Sociais), Universidade Federal de Minas Gerais (Centro de Estudos sobre a Presença Africana no Mundo Moderno), Universidade do Algarve (UALG), Instituto Superior de Ciências do Trabalho e da Empresa (Centro de Estudos Africanos, ISCTE-CEA) e a AULP.

O trabalho de catalogação e de classificação realizado nesta obra é relevante se considerarmos a condição pluriétnica de Angola e a história da constituição geográfica, organizacional e cultural desse país, tendo em conta a diversidade do povo Angolano.

Este livro é assim uma peça chave no entendimento da formação histórica e social do povo angolano e na reflexão sobre o lugar das culturas étnicas no quadro da mundialização.

Já a "Carta Fitogeográfica de Angola", escrita pelo assistente do curso superior de agronomia da Universidade de Luanda e investigador do I.I.C.A., Luís Augusto Grandvaux Barbosa (1914-1983), é reeditada por ser uma obra há muito esgotada. Originalmente editada pelo extinto Instituto de Investigação Científica de Angola, e em número muito reduzido, sendo um trabalho de referência para 
162 | RILP - Revista Internacional em Língua Portuguesa - nº 30 - 2016

todos os estudiosos das ciências biológicas de Angola, em particular para os investigadores da flora angolense.

Pode-se esperar desta obra uma atualização dos nomes científicos das plantas, bem como uma breve nota biográfica de Grandvaux Barbosa, elaboradas pelo Professor do Instituto Superior de Agronomia da Universidade de Lisboa, Ilídio Moreira, e pelos investigadores do Instituto de Investigação Científica Tropical IICT, Eurico Sampaio Martins e Maria Fernanda Pinto Basto.

A concretização deste projeto editorial da AULP, com uma tiragem de 1000 exemplares, foi resultado de uma colaboração profícua entre várias instituições: Associação de Ensino Superior em Ciências Agrárias dos Países de Língua Portuguesa (ASSESCA-PLP), Universidade Agostinho Neto (Faculdade de Ciências Agrárias do Huambo, UAN-FCAH), Universidade Federal de Minas Gerais (Instituto de Ciências Agrárias, ICA), Centro de Estudos Tropicais para o Desenvolvimento (CENTROP/ISA-UTL), Instituto Português de Apoio ao Desenvolvimento (IPAD), Ministério da Ciência e Tecnologia de Angola, Ministério da Agricultura de Angola, Ordem dos Engenheiros de Angola (OEA) e Faculdade de Medicina Veterinária da Universidade Técnica de Lisboa (FMV-UTL).

Em 2010, a AULP lança o "DITEMA - Dicionário Temático de Macau”, uma coleção de quatro volumes, em que o primeiro foi lançado por ocasião do XX Encontro da AULP realizado de 7 a 10 de Setembro na Universidade de Macau. Esta edição não se limita à história do Território, hoje R.A.E.M. - contém informação sobre os factos, os lugares, os costumes, as relações, as personagens reais e fictícias que povoam o real e o imaginário da Cidade do Santo Nome de Deus.

A ideia de organizar um "Dicionário de História de Macau" surgiu em 1998, pelo Professor António Rodrigues Baptista e subscrita com entusiasmo pela Direção do então Instituto de Estudos Portugueses. A Universidade de Macau, através da sua Comissão de Investigação Científica, acolheu com agrado e benevolência a proposta.

O volume I examina Macau de A a C. Contém informações que vão desde Ábaco, Anson, Barão George (1697-1752), Biblioteca de Macau, Budismo, Chá, Clube de Macau até Cushing, Caleb (1800-1979).

Já o volume II examina Macau de D a I. Factos, lugares, costumes, relações, personagens reais e fictícias, como D. João, Ilha Verde, Imperadores da China, Escola Portuguesa de Macau, Feira de Cantão, Vasco da Gama, até Instituto Cultural de Macau ou Itier, Alphonse Eugène Jules (1802-1877).

$\mathrm{O}$ volume III vai de $\mathrm{J}$ a $\mathrm{O}$, discutindo temas tão relevantes como os descobridores do Japão, relações de Macau com o Japão, literatura macaense, Jade, Kun Yam, Língua Portuguesa em Macau, Mercadores de Macau, ou Nanguang e Ouvidor. Por último, o volume IV examina Macau de P a Z. Padroado Português, Qianlong, Imperador, Reis de Portugal, Seda, Taiping, Ultramar, Vietname, Wei 
Yuan, Xinqiao, Yu Dayou, Zodíaco Chinês, são alguns dos temas retratados neste volume.

Sob orientação de Ernesto Rodrigues e Amadeu Ferreira, e ilustrações de Graça Morais, "A Terra de Duas Línguas - Antologia de Autores Trasmontanos" é publicada em 2011, por ocasião do XXI Encontro da AULP, em Bragança, que discutiu o tema "Novas Formas de Cooperação: Espaços de Convergência nos Países Lusófonos". Integrando a coleção de edições da AULP, entra no amplo universo académico, reunindo poesias, contos, memórias, artigos, análises e conferências escritos em português ou em mirandês, entre o final do século XIX e os dias de hoje, por autores nascidos na região de Trás-os-Montes. Esta obra pretende contribuir para manter vivo o mirandês, língua há muito falada no norte de Portugal e considerada a segunda língua oficial de Portugal desde 1999.

Com o prefácio escrito por Adriano Moreira, que enfatiza a importância da obra e defende que a globalização não é incompatível com a valorização da cultura local, este é um livro que dá a conhecer a história das artes e das letras transmontanas, bem como a rica tradição cultural local.

No mesmo ano, é publicado "Alto Trás-os-Montes - Estudo Geográfico", da autoria de Virgílio Taborda, resultado da tese de Doutoramento em Ciências Agrárias do autor. Uma obra que reúne um conjunto de informações, reflexões e sugestões interpretativas de enorme interesse e atualidade para a compreensão global das dinâmicas de desenvolvimento da região.

Este livro é uma contribuição para o estudo geográfico de Portugal, a região designada por Alto Trás-os-Montes que é uma província mergulhada no isolamento das suas montanhas e vales profundos, privado de estradas e caminhos acessíveis, de natureza rude, clima excessivo, solo em regra pouco fértil. Trás-os-Montes oferece, desde cedo, uma fisionomia peculiar que o distingue das outras regiões de Portugal.

"Os Macondes de Moçambique", é a obra comemorativa do XXII Encontro da AULP em 2012, Maputo, Moçambique. Uma edição de 4 volumes que estudam em profundidade o povo maconde até 1960: "Aspectos Históricos e Económicos" (vol. I) - Jorge Dias; "Cultura Material” (vol. II) - Jorge Dias e Margot Dias; "Vida Social e Ritual" (vol. III) - Jorge Dias e Margot Dias; "Sabedoria, Língua, Literatura e Jogos" (vol. IV) - Manuel Viegas Guerreiro.

O volume I, “Aspectos Históricos e Económicos” por Jorge Dias, é o resultado das campanhas de pesquisa etnográficas levadas a cabo pela Missão de Estudos das Minorias Étnicas no Norte da Província de Moçambique. A Missão foi criada em 1957 e chefiada pelo etnólogo Jorge Dias tendo como adjunto Dr. Manuel Viegas Guerreiro e pelo primeiro assistente Margot Schidt Dias.

"Cultura Material" (vol. II) é regido por Jorge Dias e Margot Dias, e especialmente dedicado á cultura material. Estuda se a aldeia maconde, as suas 
164 | RILP - Revista Internacional em Língua Portuguesa - nº 30 - 2016

habitações e construções destinadas a guardar animais e as reservas alimentares, maneira como se preparam os alimentos e como se come, os cuidados que os Macondes têm com o seu corpo do ponto de vista de asseio, vestuário e as diferentes mutilações.

O volume III, "Vida Social e Ritual", é trabalho baseado na recolha de material recolhido de 1956 a 1961, mas para os autores, Jorge e Margot Dias, este volume é o mais importante dos três porque nele abordam a vida social dos Macondes como um todo estrutural.

Por fim, no volume IV "Sabedoria, Língua, Literatura e Jogos”, regido por M. Viegas Guerreiro, adjunto da Missão das Minorias Étnicas do Ultramar, como o próprio nome indica, fala da sabedoria dos Macondes, o tempo e sua divisão, números e medidas, medicina e os animais, plantas e minerais do povo Macondense. Assim como, a sua Língua e Literaturas (contos) e Jogos (adivinhas).

A publicação resulta da reedição das obras originais de 1964 - resultante das campanhas de pesquisa etnográfica levadas a cabo pela Missão de Estudos das Minorias Étnicas no Norte da Província de Moçambique.

Em 2013, com o XXIII Encontro da AULP na Universidade Federal de Minas Gerais, no campus Pampulha, a Editora UFMG optou por relançar a primeira biografia de um dos personagens mais importantes da história de Minas Gerais: o escultor barroco Antônio Francisco Lisboa, o Aleijadinho. Foi assim reeditado a obra "Traços biográficos relativos ao finado Antônio Francisco Lisboa, distinto escultor mineiro, mais conhecido pelo apelido de Aleijadinho".

Reeditado por ser um livro alusivo à cultura e história do lugar sediado para o Encontro, os traços biográficos relativos ao finado Antônio Francisco Lisboa, distinto escultor mineiro, mais conhecido pelo apelido de Aleijadinho, foram escritos em 1858 pelo professor, promotor e deputado provincial mineiro Rodrigo José Ferreira Bretas, que narra o drama e os sofrimentos vividos pelo artista para materializar a sua obra.

"A nossa cultura é plural e as obras de Aleijadinho retratam a junção da nossa herança lusa, africana e autóctone. Queríamos um livro sobre um artista que nos representasse. Essa biografia que a Editora UFMG relança é pouco conhecida, mas muito interessante. O prefácio do critico cultural Silviano Santiago contextualiza a obra e a importância do Aleijadinho para o século XVIII', explicou o diretor da Editora, Wander Melo Miranda.

A obra ganhou um ensaio fotográfico produzido por Jomar Bragança, que retrata diversas criações do escultor encontradas em museus e cidades históricas mineiras, como a escultura do profeta Ezequiel que integra o patrimônio cultural de Congonhas do Campo. O livro tem também um significado especial para a Editora por ser a milésima publicação de seu catálogo. 
Antônio Francisco Lisboa, Aleijadinho, foi um importante escultor, entalhador e arquiteto do Brasil colonial. Toda a sua obra, entre talha, projetos arquitetónicos, relevos e estatuária, foi realizada em Minas Gerais, especialmente nas cidades de Ouro Preto, Sabará, São João del-Rei e Congonhas. Os principais monumentos que contêm as suas obras são a Igreja de São Francisco de Assis de Ouro Preto e o Santuário do Bom Jesus de Matosinhos. Com um estilo relacionado ao Barroco e ao Rococó, é considerado pela crítica brasileira como o maior expoente da arte colonial no Brasil.

No XXIV Encontro da AULP, em Macau, 2014, são publicados três livros: “ $O$ lúdico na história do oriente português", "The Art of Modern Portuguese Cuisine" e "A Misericórdia de Macau (Séculos XVI a XIX)".

"O lúdico na história do oriente português" escrito por Cândido do Carmo Azevedo, ex-Estado Português da Índia e atual professor coordenador do Instituto Politécnico de Macau, é um livro que "convida-nos a uma viagem. Uma viagem a efetuar pelos diversos itinerários geográficos, culturais e sociais em que se cumpriram a diáspora, a errância e a peregrinação portuguesas no Oriente. Navegando através do tempo, apresenta mosaicos reveladores dos escolhos, dos possíveis e impossíveis da miscigenação lúdica, como espelho das diferenças e assimilações no contexto mais abrangente. (...) Por tudo isto, o livro e o seu autor merecem o nosso aplauso, apreço e reconhecimento; merecem, sobremaneira, que os acompanhemos com atenção desperta e consciência inquieta na esplendorosa viagem que nos proporcionam." Jorge Olímpico Bento, Professor Catedrático da Universidade do Porto.

"The Art of Modern Portuguese Cuisine", é uma obra publicada originalmente em 2010 pelo Instituto de Formação Turística de Macau, com introdução da Dra. Fanny Vong, prefácio de David Wong e receitas de David Wong, Dell Griffin, Wong Man Su, Cheang Chi Sam e IFT Kitchen Associates. Um livro de receitas educacional com base em ingredientes tradicionais portugueses e especiarias das colónias apresentados de uma forma moderna.

Por fim, "A Misericórdia de Macau (Séculos XVI a XIX)", escrito por Leonor Diaz de Seabra, sendo uma publicação conjunta da Universidade de Macau e da Universidade do Porto, com uma tiragem de 500 exemplares, cada um com 692 páginas. O livro corresponde á tese de Doutoramento no Ramo de Conhecimento de História apresentada à Faculdade de Letras da Universidade do Porto, no dia 22 de Janeiro de 2007.

Mais recentemente, em 2015, a AULP reeditou "A ilha do fogo e as suas erupções". Esta obra fac-similada é fruto do marcante contributo do Professor Orlando Ribeiro para o conhecimento aprofundado sobre a erupção vulcânica na ilha do fogo e a sua geografia. A Professora Doutora Suzane Daveau e o Professor Doutor António Ribeiro autorizaram a realização esta edição, tendo ficado o prefácio escrito por Professor Doutor José Madeira. 
Esta edição aparece por sugestão da Universidade de Cabo Verde (Uni-CV), pela atualidade face à recente erupção do vulcão da Ilha do Fogo em novembro de 2014, sendo pertinente a concretização deste projeto editorial por ocasião do XXV Encontro da AULP - em Cabo Verde, entre 15 e 17 de julho de 2015, - com o tema "Novos desafios para o Ensino Superior após os objetivos de desenvolvimento do milénio (ODM)".

Trata-se de uma obra ímpar sobre a geografia e geologia de uma das mais emblemáticas ilhas de Cabo Verde, escrita, na sequência da erupção de 1951, pelo insigne geógrafo português. Durante os dois períodos que passou na ilha do Fogo, uma curta estada no decurso da erupção e um período mais dilatado em finais de 1952 e início de 1953, Orlando Ribeiro compilou importantíssimo acervo de informação que não se restringiu apenas aos aspetos geológicos e eruptivos, mas também á geografia física e humana daquela ilha.

O conteúdo desta obra encontra-se dividido em duas partes; a primeira trata da Geografia da ilha do Fogo, a segunda da história eruptiva da ilha, incluindo a descrição das observações efetuadas durante e após o final da erupção de 1951. Os dois temas estão ilustrados por figuras e esquemas intertexto e por um importante conjunto de fotografias reunidas em estampas no final do livro.

Ainda hoje, sessenta anos após ter sido escrita, a Ilha do Fogo e as suas erupções continua a ser uma obra de referência para quem se interesse pela ilha do Fogo, quer sejam geógrafos, geólogos ou público em geral.

Em 2016, ano em que a AULP comemora os 30 anos de atividade, são editadas duas obras comemorativas por ocasião do XXVI Encontro da AULP em Díli, Timor-Leste. "Timor-Leste: Identidade e Território" é uma memória que recorda a história do país através de um artigo escrito para a ocasião pelo investigador Fernando Augusto de Figueiredo, que tem dedicado grande parte da sua vida académica a estudar o país e a sua história. É recordado neste texto os reinos timorenses, a presença portuguesa no país, as problemáticas associadas à fronteira marítima, bem como os acontecimentos mais relevantes que levaram a bom porto a independência de Timor-Leste a 20 de maio de 2002.

Oferecido a todos os membros e participantes do Encontro, a este opúsculo junta-se ainda a relevante Planta das Operações na Pedra do Cailaco, [CA. 1727], cedida pelo Arquivo Histórico Ultramarino, que se traduz num desenho anexo a uma carta enviada pelo governador de Timor, António Moniz de Macedo, para o vice-rei de Goa, Saldanha da Gama, em 30 de Abril de 1727. Um valioso documento para a história do país, reproduzido no primeiro Encontro da AULP em Timor.

"Virtudes de algumas plantas, folhas, frutas, cascas e raízes de diferentes árvores e arbustos da Ilha de Timor" é uma obra fac-similada, cujo códice é um documento ímpar para a História Natural de Timor-Leste, com desenhos 
aguarelados que acompanham a descrição exaustiva das plantas referenciadas e a listagem de remédios que delas podem ser obtidos e que eram usados pelas gentes de Timor. Escrito e desenhado em longas folhas de papel de arroz por Frei Alberto de S. Thomaz, missionário em Timor no ano de 1749, este é um manuscrito de 64 páginas belamente ilustrado que enaltece as qualidades de etnógrafo e de naturalista do autor. Escrito entre 1788 e 1800, encontra-se conservado e guardado no Arquivo Histórico Ultramarino de Portugal.

Acompanhando a descrição das imagens, está uma lista de remédios criada por sucessivas gerações timorenses que podem ser obtidos através das plantas representadas. São 32 desenhos de plantas medicinais, acompanhadas de uma exposição ou descrição de cada uma delas. “(...) Nódoas, pisaduras, feridas, chagas, inchações, dores de corpo e de cabeça, defluxões e catarrais, febres e obstruções, indigestões, disenterias, flatos e torpores de barriga, esquinências pedras na via, gonorreias ou supressão do mês e das urinas, postemas, fraturas, ausência de tato, membros gretados, hidropézias, urinas sanguinolentas, olhos inflamados e "câmaras de sangue", bexigas, hemorroidas, envenenamentos, picadas de cobra, e mesmo para os nado-mortos na barriga das mães (...)".

No final do códice está presente uma legenda desses textos, resultado de uma leitura cuidada. Nem sempre o escriba se deixou ler e a evolução da língua não facilitou a tarefa, pelo que na legenda ainda surgem algumas interrogações que todavia são uma evolução da leitura da edição do Ministério de Ultramar de 1969, que serviu de base para esta legenda.

O valor deste documento raro do século XVIII, é ampliado ao referir-se a uma ilha do arquipélago de Sonda ainda hoje com tantos mistérios a desvendar para várias ciências. Documentos dessa época, e referentes à botânica dessa zona do globo, são raros e daí o grande interesse que merecem estes desenhos das plantas de Timor.

De Angola ao Brasil, de Cabo Verde a Portugal e passando por Macau, estas edições de manifesta riqueza cultural, contribuem para engrandecer o panorama literário e científico nos países onde se fala a língua portuguesa. Escolhidos na sua maioria pelos países de acolhimento do Encontro, a AULP serve, assim, os interesses da comunidade científica. 